Bull. Chem. Soc. Ethiop. 2014, 28(1), 121-130.

Printed in Ethiopia

ISSN 1011-3924

DOI: http://dx.doi.org/10.4314/bcse.v28i1.14

(c) 2014 Chemical Society of Ethiopia

\title{
RANDOM POLYFLUORENE $C O$-POLYMERS DESIGNED FOR A BETTER OPTICAL ABSORPTION COVERAGE OF THE VISIBLE REGION OF THE ELECTROMAGNETIC SPECTRUM
}

\author{
Desta A. Gedefaw ${ }^{1}$, Zaifei Ma ${ }^{2}$, Patrik Henriksson ${ }^{1}$, Fengling Zhang ${ }^{2}$, Mats R. Andersson ${ }^{1}$ and \\ Wendimagegn Mammo ${ }^{3 *}$ \\ ${ }^{1}$ Polymer Chemistry, Department of Chemical and Biological Engineering/Polymer Technology; \\ Chalmers University of Technology, SE-412 96 Gothenburg, Sweden \\ ${ }^{2}$ Department of Physics, Chemistry and Biology, Linköping University, SE-58183, Linköping, \\ Sweden \\ ${ }^{3}$ Department of Chemistry, Addis Ababa University, P.O. Box 1176, Addis Ababa, Ethiopia
}

(Received July 20, 2013; revised September 24, 2013)

\begin{abstract}
Two alternating polyfluorenes (APFO15-F8BT and APFO3-F8BT) with full absorption of the visible region of the electromagnetic radiation were designed and synthesized for bulk-heterojunction solar cell devices. The optical and electrochemical properties of the two polymers were studied. The two polymers exhibited strong absorption in the visible region with no significant valley over the visible region extending up to $650 \mathrm{~nm}$. Deep HOMO and ideally situated LUMO energy levels were the characteristics of the two polymers as revealed from the square wave voltammogram study: desired properties for extracting high open circuit voltage and for a facile charge transfer to the acceptor component in devices to take place, respectively. Photovoltaic devices were fabricated by blending the two polymers with PCBM[70] and up to $\sim 2 \%$ power conversion efficiency were obtained.
\end{abstract}

KEY WORDS: Polyfluorenes, Bulk-heterojunction solar cells, Optical absorption, HOMO and LUMO

\section{INTRODUCTION}

Polymer solar cells (PSCs) are thought to be the future alternatives for production of clean and cheap renewable energy in sufficient amount. In a typical device architecture known as bulk heterojunction (BHJ), a blend of conjugated polymer (donor) and PCBM (acceptor) are used together [1] to form an interpenetrating mixture. The power conversion efficiency (PCE) of such devices has shown impressive progress in the past few years reaching 7-10\% [2-5] owing to the intensive research in the synthesis of diverse types of polymers and device optimization work. The high efficiency achieved in many polymer systems has raised the hope that the commercialization of cheap PSCs is indeed a possibility in the years to come. The PCE of a PSC is determined by how high short circuit current $\left(J_{S C}\right)$, open circuit voltage $\left(V_{O C}\right)$ and fill factor $(\mathrm{FF})$ are extracted from the device prepared. In order to get high values of these device parameters, the conjugated polymer needs to fulfill essential properties of which its optical absorption behavior is one that needs considerable attention. The polymer needs to absorb strongly over a wider region of the electromagnetic radiation to harvest more photons and to improve the photocurrent extracted from the device. However, it is common to see a valley at around $500 \mathrm{~nm}$ in the absorption spectra of many polymer systems [6-7]. In order to complement the absorption valley and to possibly harvest more photons, many ways have been investigated and are known in the scientific community. The use of thick active layers [8], use of PCBM[70] instead of PCBM[60] as an acceptor [9-11], the use of a blend of two polymers having complimentary absorption [12] and the use black co-polymers consisting of segments

*Corresponding author. E-mail: wendimagegn.mammo@aau.edu.et 
absorbing in different regions are some of the ways explored for efficient photon harvesting and increasing photocurrent [13-15].

In this work, the synthesis and characteristic study of two co-polymers known as APFO15F8BT and APFO3-F8BT, which are derivatives of copolymers known as APFO-15 [16-17] and APFO-3 [18-19], respectively, is presented. APFO15-F8BT and APFO3-F8BT consist of F8BT [20] segment in addition to the parent APFO-15 [16-17] and APFO-3 [18-19] structures. It is clear that both APFO-15 [16-17] and APFO-3 [18-19] absorb poorly in the regions around $300-350 \mathrm{~nm}$ and between $450-500 \mathrm{~nm}$. F8BT [20] on the other hand absorbs strongly in this part of the electromagnetic radiation and hence its use as a co-building unit perfectly complements the absorption valleys that are seen in APFO-15 [16-17] and APFO-3 [18-19]. Hence APFO15F8BT and APFO3-F8BT were designed to eliminate the absorption valley and to have materials which absorb over the whole UV-Visible region. Indeed, the optical absorption study shows both polymers showed excellent coverage of the visible region. APFO15-F8BT and APFO3-F8BT also have a deep HOMO level as evidenced by the electrochemical studies, which is one other merit of these two copolymers. The two copolymers were tested in photovoltaic devices together with PCBM[70] and up to 2\% PCE was obtained in a preliminary device study. It is presumed that further optimization work on the devices such as the use of different processing solvents, use of high boiling solvent additives, and annealing would result in improved parameters.

\section{EXPERIMENTAL}

\section{General}

All required chemicals were bought from Sigma-Aldrich and were used as received. The optical absorption spectra of the polymers were recorded from thin films coated on glass slides from chloroform solutions using a Perkin-Elmer UV-Vis Lambda 20 spectrophotometer. Size exclusion chromatography (SEC) experiments were performed on a Waters Alliance 2000 $\mathrm{GPCV}$ instrument at $135{ }^{\circ} \mathrm{C}$ using RI detection and 1,2,4-trichlorobenzene as eluent against polystyrene standards.

\section{Square-wave voltammetry}

Square-wave voltammetry measurements were carried out on a $\mathrm{CH}$-Instruments 650A Electrochemical Workstation. A three-electrode setup consisting of platinum wires, both as working electrode and counter electrode, and a $\mathrm{Ag} / \mathrm{Ag}^{+}$quasi reference electrode was used. $\mathrm{A}$ $0.1 \mathrm{M}$ solution of tetrabutylammoniumhexafluorophosphate $\left(\mathrm{Bu}_{4} \mathrm{NPF}_{6}\right)$ in anhydrous acetonitrile was used as supporting electrolyte. The polymers were deposited onto the working electrode from chloroform solutions. The electrolyte was bubbled with nitrogen gas prior to each experiment. During the scans, nitrogen gas was flushed over the electrolyte surface. After each experiment, the system was calibrated by measuring the ferrocene/ferrocenium $\left(\mathrm{Fc} / \mathrm{Fc}^{+}\right)$ redox peak. The HOMO and LUMO energy levels of the polymers were calculated from the peak values of the third scan by setting the oxidative peak potential of $\mathrm{Fc} / \mathrm{Fc}^{+} v$. the normalhydrogen electrode (NHE) to $0.630 \mathrm{~V} \mathrm{[21]} \mathrm{and} \mathrm{the} \mathrm{NHE} v s$. the vacuum level to $4.5 \mathrm{~V}$ [22].

\section{Device fabrication}

Solar cells were fabricated with ITO glass as anode, $\mathrm{LiF} / \mathrm{Al}$ as cathode and the blend film of the polymer/PCBM[70] between the two electrodes as the active layer. The ITO glass was precleaned and modified by a conductive layer of PEDOT-PSS (Baytron P VP Al 4038). The PEDOT-PSS film was annealed at $120^{\circ} \mathrm{C}$ for $10 \mathrm{~min}$ in order to remove water. The solutions of 
conjugated polymer and PCBM[70] (1:4) weight ratio with $o$-dichlorobenzene (o-DCB) as processing solvent were spin coated on top of the PEDOT-PSS. Finally, the cathode, consisting of $\mathrm{LiF}(0.6 \mathrm{~nm})$ and $\mathrm{Al}(80 \mathrm{~nm})$, was deposited in vacuum under $5 \times 10^{-6} \mathrm{mbar}$. The thickness of the active layer was measured using a Dektak $6 \mathrm{M}$ surface profiler. The sizes of the diodes were defined by a mask to be approximately $4-6 \mathrm{~mm}^{2}$ when depositing Al. External quantum efficiencies (EQEs) were calculated from the photocurrents at short-circuit conditions. The currents were recorded by a Keithley 485 Pico ammeter under illumination of monochromatic light through the anodic side of the devices. Current-voltage characteristics were recorded using a Keithley 2400 Source Meter under illumination of AM 1.5. The light intensity of the solar simulator (Model SS-50A, Photo Emission Tech., Inc.) was $100 \mathrm{~mW} / \mathrm{cm}^{2}$. The surface morphologies of the active layers were imaged by atomic force microscopy (AFM), using a Dimension 3100 system (Digital Instruments/Veeco) operating in tapping mode. Silicon cantilevers (NSG10) with a force constant of 5.5-22.5 $\mathrm{N} \mathrm{m}^{-1}$, a resonance frequency of 190-355 $\mathrm{kHz}$ and a tip curvature radius of $10 \mathrm{~nm}$ were used.

\section{Synthesis of APFO15-F8BT}

5,8-Bis(5-bromothiophen-2-yl)-2,3-bis(3-(octyloxy)phenyl)quinoxaline $\quad$ (1) $\quad$ (0.07 g, 0.078 mmol), 4,7-dibromobenzo[c][1,2,5]thiadiazole $(2)(0.023 \mathrm{~g}, 0.078 \mathrm{mmol}), 2,2$ '-(9,9-dioctyl-9Hfluorene-2,7-diyl)bis(4,4,5,5-tetramethyl-1,3,2-dioxaborolane) (3) $(0.1 \mathrm{~g}, 0.16 \mathrm{mmol})$ and $\mathrm{Pd}\left(\mathrm{PPh}_{3}\right)_{4}(17.9 \mathrm{mg}, 0.016 \mathrm{mmol})$ were dissolved in toluene $(7.5 \mathrm{~mL})$ and heated to $100{ }^{\circ} \mathrm{C}$ for $10 \mathrm{~min}$. A $20 \%$ solution of tetraethylammonium hydroxide in water $(0.6 \mathrm{~mL})$ was added and the mixture was refluxed for $8 \mathrm{~h}$. The polymer was end-capped by adding bromobenzene $(0.12 \mathrm{~mL})$ and refluxing for $1 \mathrm{~h}$ and adding phenylboric acid $(0.17 \mathrm{~g})$. The mixture was heated for an additional $6 \mathrm{~h}$, cooled and added to a flask containing methanol and the reddish polymer formed was collected by filtration. The solid was re-dissolved in chloroform and washed twice with aqueous ammonia and then twice with distilled water. The organic phase was separated and concentrated to a small volume and added on to methanol. The solid formed was filtered and was Soxhlet extracted with diethyl ether to remove low molecular weight oligomers. The material which remained in the thimble was further extracted with chloroform and the chloroform solution was concentrated to a small volume and precipitated by adding on to methanol. The solid was collected by filtration and dried to yield APFO15-F8BT (80 mg, $61.5 \%$ ) as a brown powder.

\section{Synthesis of APFO3-F8BT}

4,7-Bis(5-bromothiophen-2-yl)benzo[c][1,2,5]thiadiazole (4) (0.04 g, $0.078 \mathrm{mmol}), 4,7-$ dibromobenzo[c][1,2,5]thiadiazole (2) $(0.023 \mathrm{~g}, 0.078 \mathrm{mmol}), 2,2$ '-(9,9-dioctyl-9H-fluorene2,7-diyl)bis(4,4,5,5-tetramethyl-1,3,2-dioxaborolane) (3) $(0.1 \mathrm{~g}, 0.16 \mathrm{mmol})$ and $\mathrm{Pd}\left(\mathrm{PPh}_{3}\right)_{4}(9$ $\mathrm{mg}, 0.008 \mathrm{mmol}, 5 \mathrm{~mol} \%)$ were suspended in a mixture of toluene $(7.5 \mathrm{~mL})$ and anisole $(2.5$ $\mathrm{mL}$ ) and heated to $120{ }^{\circ} \mathrm{C}$ to dissolve. A $20 \%$ solution of tetraethylammonium hydroxide in water $(0.56 \mathrm{~mL})$ was added and the mixture was refluxed for $6 \mathrm{~h}$. The polymer was then endcapped by adding bromobenzene $(0.12 \mathrm{~mL})$, phenylboric acid $(0.17 \mathrm{~g})$ at an interval of $1 \mathrm{~h}$ and $30 \mathrm{~min}$. After an additional $1 \mathrm{~h}$ and $30 \mathrm{~min}$, the reaction mixture was cooled and was added to a flask containing methanol and the reddish precipitate formed was collected by filtration. The solid was re-dissolved in chloroform and washed twice with aqueous ammonia and twice with distilled water. The organic phase was separated and concentrated to a small volume and added on to methanol. The solid was filtered and purified by Soxhlet extraction with diethyl ether to remove low molecular weight oligomers. The material which remained in the thimble was further extracted with chloroform and the chloroform solution was concentrated to a small 
volume and the polymer was precipitated by adding on methanol. The solid was collected by filtration and dried to afford APFO3-F8BT (59 mg, 55.7\%) as a brown solid.

\section{RESULTS AND DISCUSSION}

The chemical structures of APFO15-F8BT and APFO3-F8BT are shown in Figure 1.

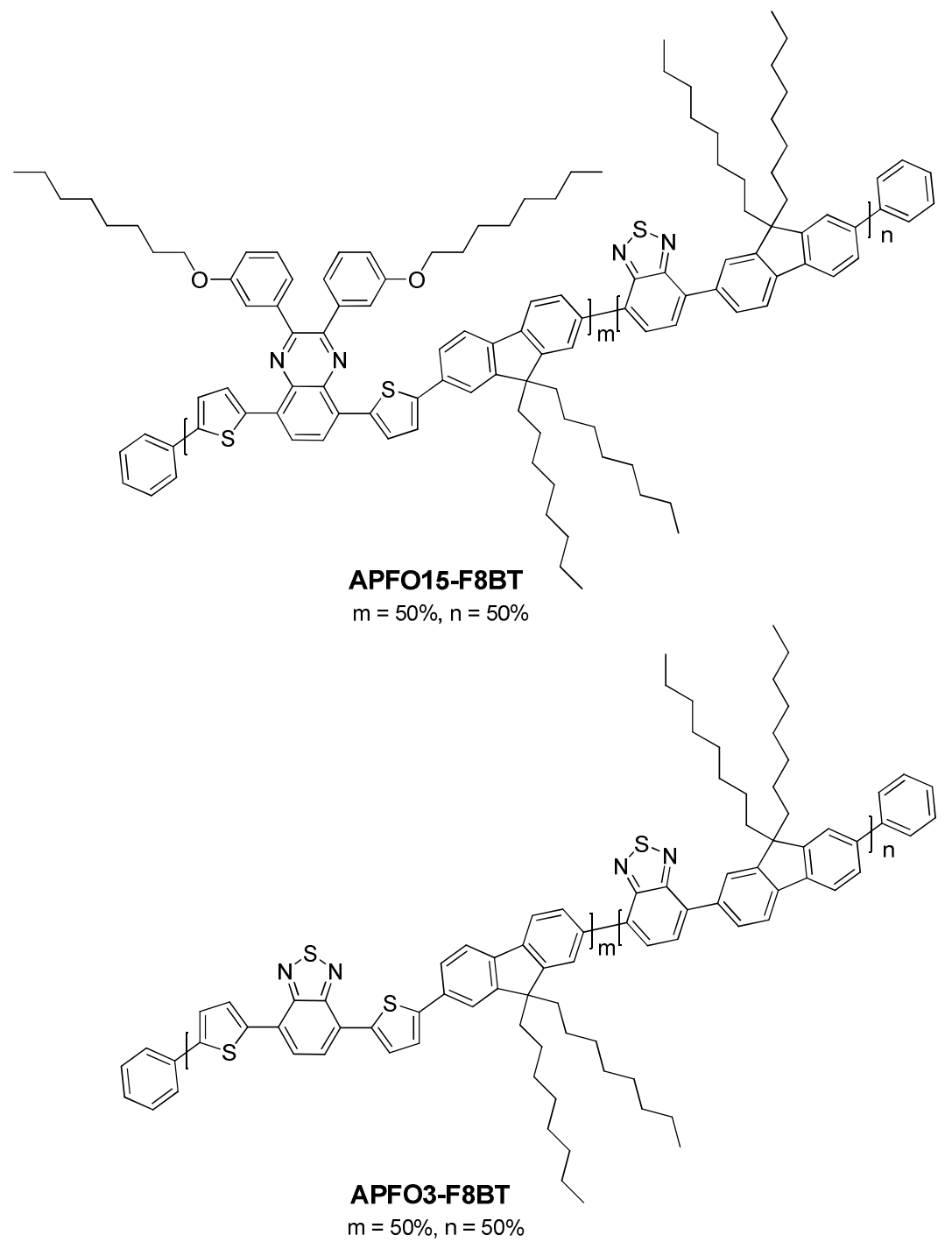

Figure 1. Chemical structures of APFO15-F8BT and APFO3-F8BT. 
Scheme 1 shows the syntheses of the two polymers. Compounds 1 [7], 2 [23], 3 [24] and 4 [18-19] were prepared following literature procedures. Thus, the palladium-catalyzed SuzukiMiyaura polycondensation reaction of 5,8-bis(5-bromothiophen-2-yl)-2,3-bis(3-(octyloxy)phenyl)-quinoxaline (1), 4,7-dibromobenzo[c][1,2,5]-thiadiazole (2) and 2,2'-(9,9-dioctyl-9Hfluorene-2,7-diyl)bis(4,4,5,5-tetramethyl-1,3,2-dioxaborolane) (3) yielded $\mathbf{P 1}$ as a red solid. On the other hand, P2 was prepared by Suzuki-Miyaura polycondensation reaction of 4,7-bis(5bromothiophen-2-yl)benzo[c][1,2,5]thiadiazole (4), 4,7-dibromobenzo[c]-[1,2,5]thiadiazole (2) and 2,2'-(9,9-dioctyl-9H-fluorene-2,7-diyl)bis(4,4,5,5-tetramethyl-1,3,2-dioxaborolane) (Scheme 1).

In terms of composition, the F8BT [20] segment accounts for $50 \%$ of the structure of APFO15-F8B T and APFO3-F8BT and the other 50\% were the APFO-15 [16-17] and APFO-3 [18-19] segments, respectively. The two polymers were purified by standard purification techniques and the number and weight average molecular weights were measured by size exclusion chromatography (SEC) using polystyrene standards. The optical absorption spectra of the thin films of APFO15-F8BT and APFO3-F8BT on glass slides are shown in Figure 2. Table 1 summarizes the molecular weights, optical and electrochemical properties of the two polymers.

$+$
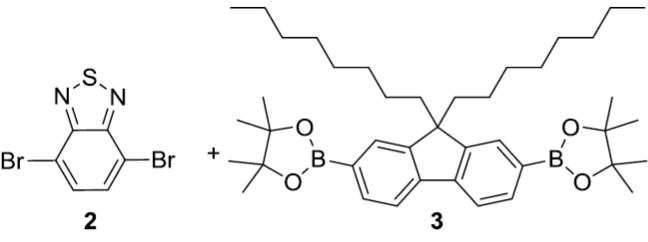

$\mathrm{Pd}\left(\mathrm{PPh}_{3}\right)_{4}$

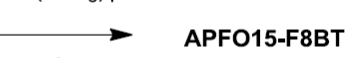

3

$\mathrm{Et}_{4} \mathrm{~N}^{+} \mathrm{OH}^{-}$

Toluene
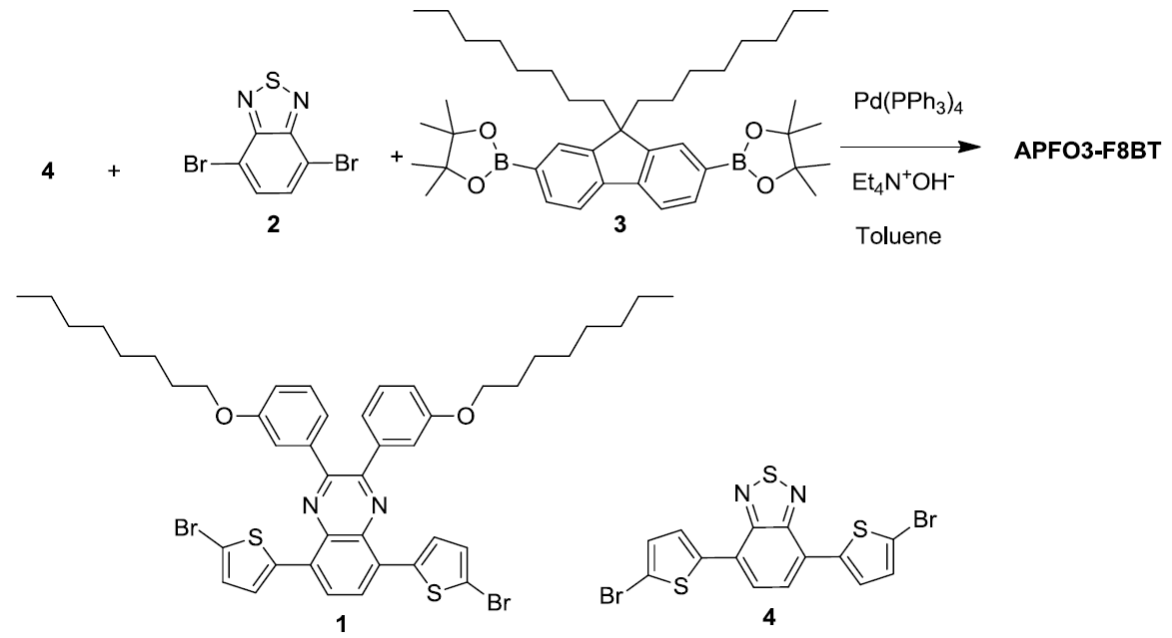

Scheme 1. Suzuki-Miyaura polycondensation reaction for the synthesis of APFO15-F8BT and APFO3-F8BT. 
Table 1. Molecular weight, absorption and electrochemical properties of the polymers.

\begin{tabular}{|c|c|c|c|c|c|c|c|}
\hline Polymer name & $\begin{array}{c}\mathrm{M}_{\mathrm{n}} \\
(\mathrm{kg} / \mathrm{mol})\end{array}$ & $\begin{array}{c}\mathrm{M}_{\mathrm{w}} \\
(\mathrm{kg} / \mathrm{mol})\end{array}$ & $\begin{array}{c}\lambda_{\text {onset }} \\
(\mathrm{nm})\end{array}$ & $\begin{array}{c}\mathrm{E}_{\mathrm{g}}{ }^{\text {opt }} \\
(\mathrm{eV})\end{array}$ & $\begin{array}{c}\mathrm{HOMO} \\
(\mathrm{eV})\end{array}$ & $\begin{array}{c}\text { LUMO } \\
(\mathrm{eV})\end{array}$ & $\begin{array}{c}\mathrm{E}_{\mathrm{g}}^{\text {elec }} \\
(\mathrm{eV})\end{array}$ \\
\hline APFO15-F8BT & 20.0 & 54.0 & 621 & 2.0 & -5.84 & -3.36 & 2.5 \\
\hline APFO3-F8BT & 17.0 & 38.0 & 641 & 1.9 & -5.90 & -3.30 & 2.6 \\
\hline
\end{tabular}

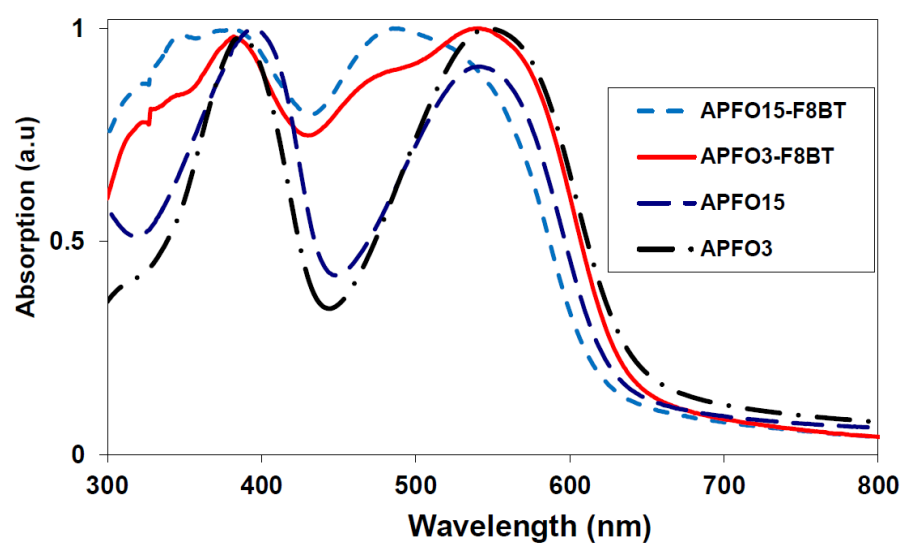

Figure 2. UV-vis absorption spectra of films of APFO15-F8BT, APFO3-F8BT, APFO15 [1617] and APFO3 [18-19] on glass slides.

Interestingly, the two polymers show strong absorption of the high energy photons (300-350 $\mathrm{nm}$ ) and in the region between $450-525 \mathrm{~nm}$. This additional absorption advantages that are observed in APFO15-F8BT and APFO3-F8BT are due to the F8BT [20] segment introduced into the parent structures. Moreover, the two polymers show onsets of optical absorption at about $630 \mathrm{~nm}$ (APFO15-F8BT) and $650 \mathrm{~nm}$ (APFO3-F8BT), which are comparable with APFO-15 [16-17] and APFO-3 [18-19], respectively. The absorption onset of APFO3-F8BT is red-shifted relative to APFO15-F8BT, which could most probably be due to the planar backbone of the polymer chains and its higher tendency to $\pi-\pi$ stack. The long alkoxy side chains that are introduced on the quinoxaline moiety of APFO15-F8BT can sterically interact with each other of the repeating units and the alkyl side chains that are attached with the fluorene. As a result of the unfavorable side chain interaction, the polymer backbone twisting can occur and hence $\pi-\pi$ intermolecular stacking of the polymer chains can be reduced as compared to APFO3-F8BT, where the steric interaction is expected to be smaller. This planar geometry could be the reason why the absorption onset in APFO3-F8BT is red shifted than APFO15-F8BT. On the other hand, in APFO3-F8BT a favorable $\pi-\pi$ intermolecular stacking of the polymer chains can form ordered arrangements and allows for a well-defined low energy absorption band to be observed as compared to the less structured low energy band that is observed in APFO15-F8BT [25]. Besides to the geometry of the backbone of the polymers, the electron accepting capacity of the quinoxaline unit in APFO15-F8BT is lower due to the electron donating alkoxy phenyl rings that are attached as compared to the benzothiadiazole unit in APFO3-F8BT. Hence, raised LUMO and a wider band gap is expected in APFO15-F8BT as compared to APFO3-F8BT [16].

The square wave voltammograms of APFO15-F8BT and APFO3-F8BT are shown in Figure 3. The HOMO energy level of APFO15-F8BT lies at $-5.84 \mathrm{eV}$, which is similar to the 
HOMO of APFO-15. The deep HOMO level is important for extracting high open circuit voltage from the solar cell devices. When it comes to the LUMO energy level, it lies at -3.36 eV, slightly lower than the LUMO of APFO-15 (-3.32 eV) [16]. This lower LUMO in APFO15F8BT could arise from the electron withdrawing effect of the benzothiadiazole unit in APFO15-F8BT and hence lowers the LUMO energy level. The HOMO and LUMO energy levels of APFO3-F8BT were measured to be $-5.9 \mathrm{eV}$ and $-3.30 \mathrm{eV}$, respectively. In this case also, the HOMO and LUMO are situated at ideal positions with even deeper HOMO position than APFO15-F8BT.

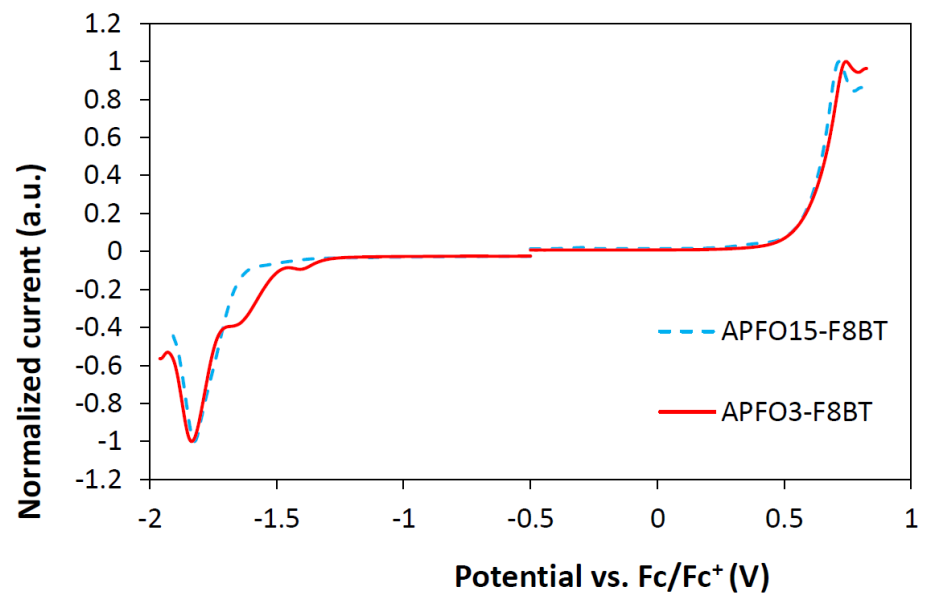

Figure 3. Square wave voltammograms of APFO15-F8BT and APFO3-F8BT.

Photovoltaic properties of the polymers were investigated in solar cell structures of ITO/PEDOT:PSS/polymer:PCBM[70]/LiF/Al. The polymer and PCBM[70] blends were mixed in 1:4 mixing ratio and were spin-coated from $o$-DCB solution and representative photovoltaic data is summarized in Table 2.

Table 2. Photovoltaic performances of devices made from APFO15-F8BT:PCBM[70] and APFO3F8BT:PCBM[70] using $o$-DCB as a processing solvent.

\begin{tabular}{|l|c|c|c|c|c|c|}
\hline $\begin{array}{l}\text { Polymer: } \\
\text { PCBM[70] }\end{array}$ & $\begin{array}{c}\text { Spin Speed } \\
(\mathrm{rpm})\end{array}$ & $\begin{array}{c}J_{S C} \\
\left(\mathrm{~mA} / \mathrm{cm}^{2}\right)\end{array}$ & FF & $\begin{array}{c}V_{O C} \\
(\mathrm{~V})\end{array}$ & $\begin{array}{c}\text { Thickness } \\
(\mathrm{nm})\end{array}$ & $\begin{array}{c}\text { PCE } \\
(\%)\end{array}$ \\
\hline \multirow{2}{*}{$\begin{array}{l}\text { APFO15- } \\
\text { F8BT:PCBM[70] }\end{array}$} & 1500 & 6.21 & 0.38 & 0.83 & 80 & 1.99 \\
\cline { 2 - 7 } & 2000 & 6.05 & 0.40 & 0.87 & 65 & 2.26 \\
\cline { 2 - 7 } & 2500 & 5.87 & 0.44 & 0.79 & 55 & 2.06 \\
\hline $\begin{array}{l}\text { APFO3- } \\
\text { F8BT:PCBM[70] } \\
(1: 4)\end{array}$ & 1500 & 5.80 & 0.37 & 0.86 & 70 & 1.91 \\
\cline { 2 - 7 } & 2000 & 5.22 & 0.41 & 0.89 & 65 & 1.92 \\
\cline { 2 - 7 }
\end{tabular}

Figure 4 shows the EQEs of the devices fabricated as a function of wavelength. The photocurrent generation starts from nearly $700 \mathrm{~nm}$ for which the maximum photocurrent generation is reaching about $55 \%$ at a wavelength of around $\sim 450 \mathrm{~nm}$ for both polymers together with PCBM[70]. The high EQE at $\sim 450 \mathrm{~nm}$ could be because of the strong absorption of the polymers due to the additional F8BT [20] segments and the contribution of PCBM[70] 
[9-11] for charge carrier generation. The slight mismatch between the EQE curves (Figure 4) and the optical absorption spectra (Figure 2) could probably arise from the loss of excitons formed because of quenching and or recombination of separated charge carriers due to the unfavorable blend morphology (Figure 5).
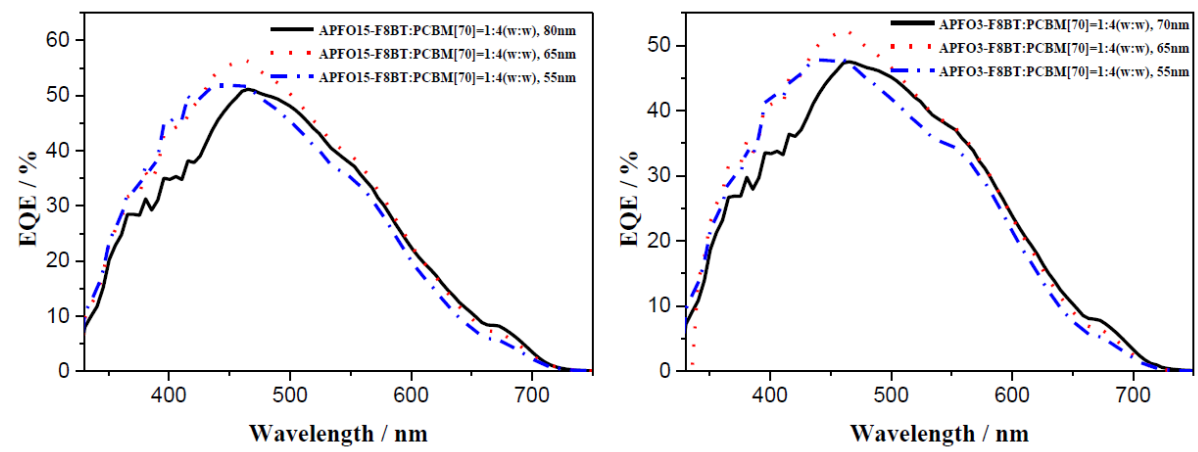

Figure 4. Plots of the EQEs of solar cell devices containing APFO15-F8BT:PCBM[70] and APFO3-F8BT:PCBM[70] in 1:4 mixing ratios and different film thicknesses using $o$ $\mathrm{DCB}$ as a processing solvent.
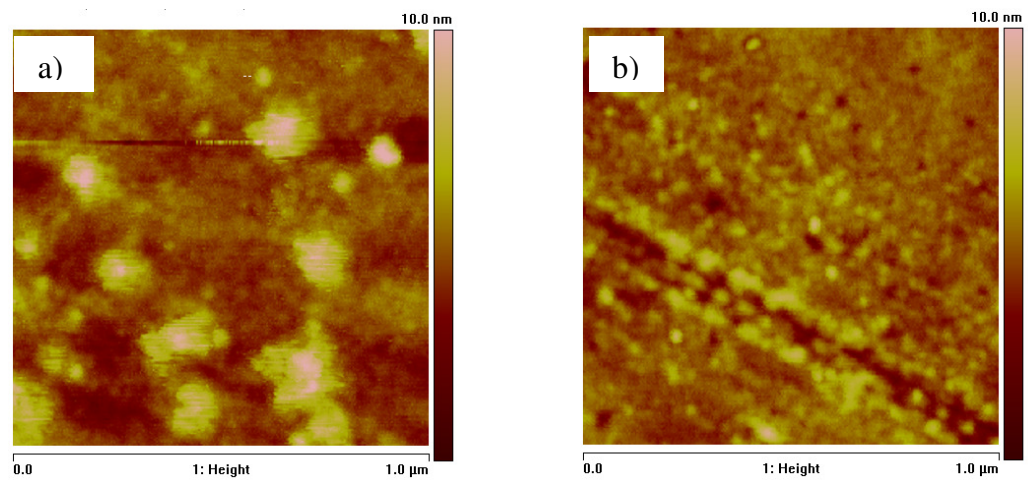

Figure 5. AFM image of 1:4 blend of APFO15-F8BT:PCBM[70] (a) and APFO3F8BT:PCBM[70] (b) with $o$-DCB processing solvent.

The best performing device was prepared from APFO15-F8BT:PCBM[70] in 1:4 blend ratio with a $65 \mathrm{~nm}$ film thickness which showed PCE of $2.26 \%$ with corresponding $J_{\mathrm{SC}}$ of 6.05 $\mathrm{mA} / \mathrm{cm}^{2}, \mathrm{FF}$ of $40 \%$ and a decent $V_{\mathrm{OC}}$ of $0.87 \mathrm{~V}$. The maximum PCE obtained from a blend of APFO3-F8BT:PCBM[70] in 1:4 mixing ratio on the other hand was $1.9 \%$ with corresponding $J_{\mathrm{SC}}$ of $5.22 \mathrm{~mA} / \mathrm{cm}^{2}$, FF of $41 \%$ and $V_{\mathrm{OC}}$ of $0.89 \mathrm{~V}$ for a film thickness of $65 \mathrm{~nm}$. Figure 5 shows the AFM image of the photoactive blend of the best performing devices. It is seen that there are isolated regions due to the polymer and fullerene phase separation. This kind of isolated regions is unfavorable to form interconnected pathways in the active layer, thus limit the charge carrier transport in the active layer, inducing low FF and low photocurrent obtained by the solar cell and ultimately affect the power conversion efficiency of the devices. It is clear that the issue of 
morphology is complex and its manipulation is very crucial to achieve high PCE in PSCs. Some of the techniques that are commonly used to modify film morphology include film annealing, use of appropriate processing solvent/s and use of high boiling solvent additives. Particularly, the use of high boiling solvent additives such as 1-chloronaphthalene $(\mathrm{CN})$ and 1,8diiodooctane (DIO), is widely utilized to prevent aggregation of polymer and acceptor domains [26-27] and yield appropriately sized phase separated domains. In our case, as seen from the AFM images, the highly isolated polymer and acceptor domains could possibly have been minimized by using solvent additives to help in forming homogenously distributed blend mixture for good charge carrier formation and transport.

\section{CONCLUSIONS}

Two polyfluorene copolymers were designed and synthesized with the main aim of improving the optical absorption behaviors of the two polymers. Indeed, it was demonstrated that the insertion of F8BT segment into the polymer backbone improved the optical absorption coverage of the polymers. The F8BT unit absorbs high and medium energy photons and perfectly complements the region where most low band gap polymers are lacking to absorb. The two polymers were found to have deep HOMO energy level that is desired for extracting high open circuit voltage. The devices fabricated from APFO15-F8BT together with PCBM[70] in a 1:4 blend ratio resulted a decent $V_{O C}$ reaching to $0.9 \mathrm{~V}$ and a PCE reaching to $2.2 \%$. The PCE obtained from a blend of APFO3-F8BT:PCBM[70] in 1:4 mixing ratio on the other hand was $1.9 \%$ with corresponding $J_{S C}$ of $5.22 \mathrm{~mA} / \mathrm{cm}^{2}$, FF of $41 \%$ and a decent $V_{O C}$ of $0.89 \mathrm{~V}$. In both cases the modest $J_{S C}$ and FF obtained could be because of the unfavorable blend morphologies as seen from AFM study. We believe that further optimization of the morphology by using appropriate solvent additives could result in a more homogeneous blend film which would possibly help to improve the $J_{S C}$, FF and ultimately the PCE of the solar cell devices.

\section{ACKNOWLEDGMENTS}

D. Gedefaw and W. Mammo acknowledge financial support from the International Science Programme (ISP), Uppsala University, Sweden.

\section{REFERENCES}

1. Yu, G.; Gao, J; Hummelen, J.C.; Wudl, F.; Heeger, A. J. Science 1995, 270, 1789.

2. Price, S.C.; Stuart, A.C.; Yang, L.Q.; Zhou, H.X.; You, W. J. Am. Chem. Soc. 2011, 133, 4625.

3. Chen, H.C.; Chen, Y.H.; Liu, C.C.; Chien, Y.C.; Chou, S.W.; Chou, P.T. Chem. Mater. 2012, 24, 4766.

4. Zhou, H.X.; Yang, L.Q.; Stuart, A.C.; Price, S.C.; Liu, S.B.; You, W. Angew. Chem. Int. Ed. 2011, 50, 2995.

5. Dou, L.; Yoshimura, K.; Ohya, K.; Chang, W.; Gao, J.; Liu, Y.; Richard, E.; Yang, Y. Macromolecules 2013, 46, 3384.

6. Hellström, S.; Lindgren, L.J.; Zhou, Y.; Zhang, F.L.; Inganäs, O.; Andersson, M.R. Polym. Chem.-UK 2010, 1, 1272.

7. Gedefaw, D.; Zhou, Y.; Hellström, S.; Lindgren, L.; Andersson, L.M.; Zhang, F.L.; Mammo, W.; Inganäs, O.; Andersson, M.R. J. Mater. Chem. 2009, 19, 5359.

8. Lenes, M.; Koster, L.J.A.; Mihailetchi, V.D.; Blom, P.W.M. Appl. Phys. Lett. 2006, 88. 
9. Wienk, M.M.; Kroon, J.M.; Verhees, W.J.H.; Knol, J.; Hummelen, J.C.; van Hal, P.A.; Janssen, R.A.J. Angew. Chem. Int. Ed. 2003, 42, 3371.

10. Wang, X.J.; Perzon, E.; Oswald, F.; Langa, F.; Admassie, S.; Andersson, M.R.; Inganäs, O. Adv. Funct. Mater. 2005, 15, 1665.

11. Arbogast, J.W.; Foote, C.S. J. Am. Chem. Soc. 1991, 113, 8886.

12. Mammo, W.; Gadisa, A.; Zhang, F.; Inganäs, O.; Andersson, M.R. Sol. Energy Mater. Sol. Cells 2007, 91, 1010.

13. Zhu, Z.G.; Waller, D.; Gaudiana, R. J. Macromol. Sci. A 2007, 44, 1249.

14. Zhou, Y.; Gedefaw, D.A.; Hellström, S.; Kratschmer, I.; Zhang, F.L.; Mammo, W.; Inganäs, O.; Andersson, M.R. IEEE J. Sel. Top. Quantum Electron. 2010, 16, 1565.

15. Yue, W.; Zhao, Y.; Tian, H.K.; Song, D.; Xie, Z.Y.; Yan, D.H.; Geng, Y.H.; Wang, F.S. Macromolecules 2009, 42, 6510.

16. Gadisa, A.; Mammo, W.; Andersson, L.M.; Admassie, S.; Zhang, F.; Andersson, M.R.; Inganäs, O. Adv. Funct. Mater. 2007, 17, 3836.

17. Lindgren, L.J.; Zhang, F.; Andersson, M.; Barrau, S.; Hellström, S.; Mammo, W.; Perzon, E.; Inganäs, O.; Andersson, M.R. Chem. Mater. 2009, 3491.

18. Inganäs, O.; Svensson, M.; Zhang, F.; Gadisa, A.; Persson, N.K.; Wang, X.; Andersson, M.R. Appl. Phys. A 2004, 79, 31.

19. Svensson, M.; Zhang, F.; Veenstra, S.C.; Verhees, W.J.H.; Hummelen, J.C.; Kroon, J.M.; Inganas, O.; Andersson, M.R. Adv. Mater. 2003, 15, 988.

20. Lange, A.; Krueger, H.; Ecker, B.; Tunc, A.V.; von Hauff, E.; Morana, M. J. Polym. Sci. Part A: Polym. Chem. 2012, 50, 1622.

21. Pavlishchuk, A.W.A.V.V. Inorg. Chim. Acta 2000, 298, 97.

22. Bard, A.J.; Faulkner, L.R. Electrochemical Methods: Fundamentals and Applications, Wiley: New York; 2001.

23. Tao, H.-Y.L.Y.-M.; Xu, Q.-L.; Zhu, Y-C.; Kang, L-C.; Zheng, Y-X.; Zuo, J-L.; You, X-Z. Synth. Met. 2011, 161, 718.

24. Ranger, M.; Rondeau, D.; Leclerc, M. Macromolecules 1997, 30, 7686.

25. Wang, E.; Vandewal, K.; Ma, Z.; Hou, L.; Lundin, A.; Himmelberger, S.; Salleo, A.; Müller, C.; Inganäs, O.; Zhang, F.; Andersson, M.R. Adv. Energy Mater. 2013, 3, 806.

26. Hoven, C.V.; Dang, X.-D.; Coffin, R.C.; Peet, J.; Nguyen, T.-Q.; Bazan, G.C. Adv. Mater. 2010, 22, E63.

27. Kim, Y.; Yeom, H.R.; Kim, J.Y.; Yang, C. Energy Environ. Sci. 2013, 6, 1909. 